Wegener's hypothesis, and emphasises the fact that supporters of that hypothesis must look elsewhere than to the facts of animal and plant distribution for positive evidence in its support. Zoologists and botanists are dependent on the geologist and geophysicist for the correct interpretation of the palæogeographical changes which have taken place in the earth, and must be guided by them in selecting the basis on which the known geographical distribution of living forms can be explained.

The Writer of the Article.

\section{Use of the Triode Valve in Spectrometry.}

THE three-electrode valve offers a very simple and trustworthy method of amplifying the small currents produced in the thermopile of an infra-red spectrometer. Bright lines are more readily picked up and the limits of absorption bands determined with greater certainty with a valve and telephone than with a galvanometer. Moreover, the valve is instantaneous in action, while a sensitive galvanometer takes an appreciable time to give a trustworthy indication-so much so that the fainter lines are apt to be missed when using a long-period galvanometer. In the thermopile circuit an interrupter is necessary: this may take the form of a steel wire maintained in vibration electrically to which is attached a small wire dipper making contacts through a cup containing mercury. The interrupted thermopile current is passed through the primary of a small step-up transformer the secondary of which is connected to the grid of the valve.

For quantitative work the thermopile current is balanced by a potentiometer, a minimum of sound in the telephones indicating the point of balance.

The valve has a further advantage over the galvanometer in that it is unaffected by vibration or stray magnetic fields. The use of a valve for such work would seem to have many other applications, and to this end further experiments are being carried out.

L. Bellingham.

$$
\begin{gathered}
71 \text { Hornsey Rise, } \\
\text { London, N.I9, } \\
\text { March } 22 .
\end{gathered}
$$

\section{The Release of Electrons by X-rays.}

IN his interesting article, " Recent Advances in Photographic Theory," in NATURE of March 24, Dr. Mees touches upon the nature of X-rays and the mechanism of their production, and quotes Sir William Bragg's analogy of the plank of wood dropped into the sea.

I believe that Sir William Bragg put forward this analogy in a Robert Boyle Lecture, rather with a view towards successfully visualising the electron$\mathrm{X}$-ray process than of proving an individual relationship between them. One is tempted to say that an analogy never proves anything, although it may be thoroughly illuminating.

It is an extraordinary fact that a beam of X-rays will release electrons from an object which they hit, with just the velocity of the stream that originates the rays; it appears probable from energy considerations that this relation cannot hold down to the individual electron, so it might not be unprofitable if experiments were directed towards finding the limiting strength of the stream of electrons for the production of $\mathrm{X}$-rays.

S. Russ. Physics Department

The Middlesex Hospital, W.I, March 26.

NO. 2790 , VOL. I I I ]

\section{The Magnetic Disturbance of March 24-25.}

A CONSIDERABLE magnetic disturbance occurred on March 24-25, as recorded by the Stonyhurst magnetographs. There was no marked sudden commencement of the disturbance, but the declination magnet began to move steadily towards the W., accompanied by a decrease in horizontal force, between the hours 8 and 9 G.M.T. The declination magnet attained the extreme limit of its westerly movement at I3 h. I4 m., when it began to move gradually towards the $\mathrm{E}$. At $\mathrm{I} 7 \mathrm{~h}$. I $2 \mathrm{~m}$. a period of rapid oscillations commenced on the declination magnet. On the horizontal force magnet the decrease in force was succeeded, at $\mathrm{I} 2 \mathrm{~h} .24 \mathrm{~m}$., by an increase. A very rapid oscillation of increase and decrease occurred between I $7 \mathrm{~h} .2 \mathrm{~m}$. and I $7 \mathrm{~h}$. I $8 \mathrm{~m}$., the range being $88 \gamma$ (I $\gamma \equiv \mathrm{IO}^{-5}$ C.G.S. unit).

A quieter period ensued on the declination magnet between I $8 \mathrm{~h} .24 \mathrm{~m}$. and $2 \mathrm{I} \mathrm{h}$. I $2 \mathrm{~m}$., while the horizontal force magnet, after the rapid oscillation at $\mathrm{I} / \mathrm{h}$, $2 \mathrm{~m}$., showed a gradual decrease in force, which reached its limit at I 8 h. $48 \mathrm{~m}$. A remarkable rapid oscillation, to E. and return to W., occurred on the declination magnet, between $2 \mathrm{I} \mathrm{h}$. I2 m. and $2 \mathrm{I} \mathrm{h}$. $26 \mathrm{~m}$., the range of the oscillation being $38^{\prime}$. This was accompanied on the horizontal force magnet by an even more noteworthy rapid oscillation of increase and decrease of force, of range $189 \gamma$, between $2 \mathrm{I} \mathrm{h}$. $24 \mathrm{~m}$. and $2 \mathrm{I} \mathrm{h} .50 \mathrm{~m}$.

The only other notable feature of the disturbance was a bay in both elements, between March $25,2 \mathrm{~h}$. I2 $\mathrm{m}$., and $3 \mathrm{~h}$. o m., the range in declination being $16^{\prime}$, and in horizontal force $97 \gamma$. The more violent phases of the storm had ceased by March 25, $8 \mathrm{~h}$. The extreme ranges were, in declination $\mathrm{r}^{\circ} 6^{\prime}$, and in horizontal force $238 \gamma$. The vertical force magnet showed a general movement, with oscillations, of increase and decrease of force between the hours March 24, I7 h. I2 m., and March 25, 4 h. 24 m. This would indicate the period of the greatest activity of the disturbance. The sensibility of the magnet is uncertain, but the extreme range was about $80 \gamma$.

A disturbed period in magnetic activity occurred on February $25^{-28}$, so that this storm follows after an interval of 27 days, the synodical rotation period of the sun. But the solar surface has been unusually quiet during the past two months, at least so far as spots, which have been very few and of small area, and faculæ, which have been very faint, are concerned. The connexion of these disturbances with solar phenomena will require further elucidation. Father Dechevrens, S.J., recorded strong earthcurrents at his observatory, St. Louis, Jersey, during the February disturbance. It will be interesting to hear of any observations of aurora borealis.

Stonyhurst College Observatory A. L. CoRTiE, S.J April 3 .

\section{Pressure of Fluidity of Metals.}

Mr. Hugh O'NeILL, in his letter in NATURE of March 3I, p. 430, gives what he calls $\mathrm{H}_{u}$, the " ultimate hardness " of tin, zinc, and steel. On referring to my letter at p. I7 of NATURE of January 6 , it will be seen that $\mathrm{H}$ is there used for $\mathrm{H}_{u}$, and that the pressure of fluidity =twice the ultimate hardness. The units of $\mathrm{H}_{u}$ given at p. 430 are evidently kilograms per sq. mm. Expressing these in kilos per sq. $\mathrm{cm}$. and multiplying by 2 we obtain the following values of the pressures of fluidity as calculated by Mr. O'Neil 